\title{
GEOGRAFIA DA COOPERAÇÃO INTERNACIONAL PARA O DESENVOLVIMENTO: UM OLHAR ESTRATÉGICO DAS RELAÇÕES BRASIL- ÁFRICA NO INÍCIO DO SÉCULO XXI
}

\author{
André Santos da ROCHA \\ Departamento de Geografia, PPGGEO- UFRR \\ asrrgeo@gmail.com/ asrgeo@ufrri.br
}

\begin{abstract}
Resumo
No atual contexto mudial algumas estratégias são tomados por países que querem se projetar politicamente e economicamente. Uma destas estratégias é fomentar, através de sua politica externa os acordos de cooperação internacional. A cooperação Internacional tem seu marco nos rumos do desenvolvimento mundial do pós segunda guerra, e tem assumido um papel importante para alguns países, em especial os emergentes. Neste cenário se destaca o Brasil, que adotou como estratégia ampliar suas ações para cooperação com países do Sul Global, dando especial ênfase a cooperação técnica e econômica com países do Continente africano. Apontamos que o desenvolvimento desta atividade serve de exemplo de uma estratégia geopolitica que permite territorialização de empresas e instituições brasileiras na África bem como a projeção da hegemonia do Brasil no sistema internacional.
\end{abstract}

Palavras Chave: Cooperação Internacional; Relações Sul-Sul; Geografia Política; Brasil-África.

\begin{abstract}
In the current world context some strategies are taken by countries that want to project politically and economically. One of these strategies is to foster, through its foreign policy, international cooperation agreements. International cooperation has its milestone in the direction of world post-Second war development, and has played an important role for some countries, especially emerging ones. In this scenario we highlight Brazil, which adopted as a strategy to broaden its actions for cooperation with countries of the Global South, giving special emphasis to technical and economic cooperation with countries of the African continent. We point out that the development of this activity serves as an example of a geopolitical strategy that allows territorialization of Brazilian companies and institutions in Africa as well as the projection of Brazil's hegemony in the international system.
\end{abstract}

keywords: International cooperation; South-South relations; Political geography; Brazil-Africa.

\section{Introducão}

A construção de uma agenda de Cooperação Internacional para o Desenvolvimento (CDI) tem seu marco institucional no contexto pós Segunda Guerra Mundial, com a criação do Plano Marshall na ajuda dos Estados Unidos para Europa (Milani,2012). Para além de ser uma ajuda mútua para superação de problemas econômicos, sociais e técnicos enfrentados pelos países centrais e periféricos, entendemos que a cooperação entre os países também assume um olhar estratégico 
quanto à projeção da Hegemonia e territorialização das ações dos diferentes atores que são envolvidos.

Desde a segunda metade do século XX, o sistema-mundo vem experimentando transformações sensíveis em sua estrutura geopolítica, culminando na constituição de uma forma complexa de interpretação das relações de poder. Dentre essas mudanças, podemos citar emergência de novos polos de poder, na figura de Estados como potências Regionais que alçam esforços de projeção global, como é o caso dos BRICS - Brasil, Rússia, índia e China e África do Sul - que alcançaram no século XXI o status de potência emergentes (Stuenkel, 2017).

A atuação destes países no sistema internacional vem desenhando uma nova geografia econômica e um novo quadro no contexto da geografia dos poderes. Neste contexto, percebe-se a constituição de novas estratégias, que incluem pensar a Cooperação Internacional para o Desenvolvimento (CDI) que são adotadas por esses países como formas de extensão de seu poderio técnico e econômico. Parte destes países emergentes acabaram por adotar a estratégia da cooperação internacional baseada na perspectiva Sul-Sul, que significa privilegiar ações entre países do mundo periférico e semiperiférico (Pautasso,2010). Essa perspectiva tem se constituído como uma alternativa estratégica para consolidação de suas forças no mundo.

O exemplo Brasileiro é singular, pois no início do século XXI adotou uma mudança no paradigma de sua política externa ao dar maior ênfase nas relações Sul-Sul, em especial após o ano de 2003, na qual ganhou destaque os projetos de cooperação técnica e as aproximações econômicas com o continente africano. Para apresentar essas discussão, dividiremos o texto em duas principais partes, a saber: [1] Geografia da Cooperação Internacional: uma revisão - nesta parte apresentaremos uma revisão onde expomos as possibilidades de análise do cenário internacional tomando os conceitos da geografia para leituras das transformações desencadeadas pelos acordos de cooperação; e [2] Um olhar para cooperação brasileira como a África no século XXI - um olhar para cooperação técnica - aqui destacaremos a construção do perfil da política externa brasileira em torno da Cooperação Sul-Sul (CSS), que se constituiu no início do século XXI e apresentaremos as possíveis leituras de uma cartografia dos projetos de cooperação técnica desenvolvidos no continente.

\section{Geografia da Cooperação Internacional - uma Revisão.}

Esse primeiro tópico nos abre um precedente de uma revisão bibliográfica e metodológica para pesar: como se estruturam os estudos de cooperação internacional na geografia; e quais os indicativos para a análise de processo globais-regionais que materializam as dinâmicas atuais de cooperação.

Em primeiro lugar, não se quer aqui criar uma nova epistemologia geográfica, desse modo optamos que validar a concepção de geografia que se baseia em entender os "horizontes espaciais da sociedade" (Valcarcel,2000) que corrobora na noção de que a lógica espacial envolve $n$ elementos que incluem as forças políticas, econômicas, culturais, ambientais que promovem transformações, apropriações, projeções e intervenções sensíveis, ou não, e que adquirem forma e 
função na organização das sociedades. Neste sentido, como estatuto prático, no campo da geografia em articulação a política (Sanguin, 2016) não podemos ignorar a possibilidade de pensar como lógicas geográficas de análises os estudos que envolvem os associativismos políticos, das ideologias geográficas, das formas de apropriação territorial, da regionalização econômica, e das demandas de cooperação, seja local ou internacional.

Tendo a cooperação, como uma dimensão de análise possível, na qual se insere a proposta deste trabalho, se torna necessário pensarmos o que podemos entender por cooperação. De um modo geral, o termo "cooperação" é extremamente polissêmico, uma vez que pode traduzir uma série de questões - em nível técnico, econômico, diplomático, cultural, militar-defesa, associativismo regional, entre outras. Ela pode tratar tanto no sentido da promoção de níveis equivalentes de desenvolvimento, quanto mascarar uma nova roupassem colonial, na medida que trabalha a perspectiva da transferência de desenvolvimento (Lima \& Milani, 2016). Todavia, em sua natureza, independente da amplitude de ações que envolve, o entendemos como um estatuto político de ação na qual muitos países têm tomado como estratégia geopolítica.

Assim, apoiado na concepção de política da Hannah Arendt (2009), podemos pensar a cooperação como uma forma lógica de "exercício de poder com os outros" (Allen, 2003), uma vez que ela envolve uma miríade de acordos que permitem alcançar objetivos comuns, ou parcialmente coletivos dos membros inseridos numa cooperação, e que tem em sua natureza uma dimensão espacial fundante, em especial porque envolve dimensões territoriais e projeções hegemônicas em diferentes escalas (Rocha, 2014).

Os estudos sobre o tema da cooperação assumiram lugar comum na literatura no campo científico da Economia, da Ciência Política, da História e das Relações Internacionais. No campo da geografia brasileira e latino-americana, esse tema ganhou pouca ênfase tendo sua presença em pesquisas que tratam de temas isolados sem uma proposta teórico-metodológica organizada. Todavia, alguns estudos vêm emergindo de forma mais sistemática no mundo, com o destaque da Geografia Italiana com os estudos de Valério Bini (2016) e Egídio Dansero et. All (2008) e na Geografia inglesa com Emma Mawdsley (2015) Danilo Marcondes e Emma Mawdsley (2017).

No que tange aos estudos, sobre cooperação internacional na geografia é possível traçar uma grande aproximação com o tema desenvolvimento. Neste sentido, observamos, pelo menos duas tendências analíticas de forma sistematizada e com diferentes abordagens sobre o tema, que em resumo apontam: [a] de um lado com um olhar mais macro das tendências internacionais (abordagem anglo-saxónica), e [b] de outro uma tendência para uma certa aproximação sobre os efeitos locais-regionais de forma empírica (abordagem italiana).

Dentro da primeira abordagem, numa perspectiva anglo-saxã, em especial aquela produzida no Reino Unido, com destaque para os estudos da Emma Mawdsley - evidenciamos os estudos dos processos de cooperação associados ao funcionamento da lógica capitalista de poder no enquadramento do sistema-mundo wallenteiniano. Os estudos são sistematizados tentando entender o funcionamento das cooperações, sejam elas qualificadas em Sul-Sul ou Norte-Sul, dentro de uma repercussão em escala mundo, que tenta entender os desdobramentos no modelo de acumulação e expropriação no sistema capitalista, sobretudo na tentativa de entender os desdobramentos das 
"mudanças no sistema internacional de desenvolvimento". Neste campo são inseridas questões como soberania, hegemonia, sistema-internacional e desenvolvimento como categorias essenciais para leituras do tema da cooperação internacional, tendo sobretudo as ações dos Estados como elemento de análise (Mcewan \& Mawsdley, 2012).

$\mathrm{Na}$ outra abordagem, sistematizada no corpo da geografia Italiana, destacam-se os trabalhos do grupo GECO', em especial ganha destaque os debates de Egídio Densero e Valerio Bini que organizam estudos sobre a temática da cooperação internacional também associado à perspectiva do desenvolvimento. A abordagem da perspectiva italiana, se esforça em entender os desdobramentos da relação geografia e cooperação também numa base territorializadora, onde pode-se averiguar os efeitos em dimensões locais e regionais. Nesta abordagem é possível pensar, conforme aponta CECO (2016, p. 349) "uma geografia da cooperação", mas também uma "geografia na cooperação" e uma "geografia para cooperação". A primeira se relacionaria a abordagem mais comum - ligadas a formações de alianças no sistema internacional identificando países doadores e países receptores ou beneficiários. A segunda e a terceira se relacionariam a proposta mais instrumental de pesar uma aplicação - geografia a serviço da cooperação e os seus desdobramentos - a geografia em níveis regionais que são produzidos.

Diante dos esforços de revisão e leituras de pesquisa entendemos a importância de ampliar o olhar geográfico sobre o tema da cooperação Internacional. Assim, se fazem mister, a interface destas abordagens a partir de multiescalaridade dos fenômenos. O tema da cooperação e da política externa são indicativos de uma faceta geopolítica - que permite uma análise de projeção hegemônica e de transformações territoriais que envolvem múltiplos atores (Estados, empresa, órgãos de pesquisa, ongs, etc.) e suas intencionalidades.

Neste sentido, com base nos estudos realizados nos últimos anos podemos apontar como elementos de análise para o campo da cooperação:

[a] a projeção hegemônica e geopolítica que media novas relações de poder que permite analisar as estratégicas traçadas pelos países no que tange a dimensão diplomáticas em acordos de cooperação, permitindo uma qualificação seja ela SulSul ou Norte-Sul no geoeconomia do sistema mundo, seja ela mais heterodoxa ou mais pragmática (Mawdsley, Kim, Marcondes,2017; Marcondes \& Mawdley,2017; Rocha,2014), ;

[b] a transformação material no território - que indica a "geografia na cooperação" através da visualização e compreensão dos modelos de integração regional e 0 mapeamento da territorialização de instituições oriundos da cooperação (Bini,2016; Densero Et All, 2008);

e [c] a promoção geoeconômica de regiões criando circuitos de capitais e de cooperação - indicativo da materialização de micro-regiões econômicas vistos nos inúmeros acordos regionais e blocos econômicos podem ser produzidos.

É ponto pacífico que vivenciamos um novo tempo na geoeconomia mundial (Hurrel, 2009) onde a cooperação assume um lugar estratégico na agenda de muitos países. Na tentativa de avaliar

\footnotetext{
${ }^{1}$ Geco é uma assinatura coletiva do grupo "Geografia, cooperação para o desenvolvimento e desenvolvimento local" que envolve uma série de pesquisadores italianos de diferentes universidades. Destacando os estudos na universidade de Turin e Milão.
} 
estas questões apontaremos aqui algumas considerações sobre a política externa brasileira, que foi empregada no início do Século XXI, em especial desenhando novos contornos geoeconômicos e geopolíticos, ao projetar sobre o continente africano sua plataforma de ação.

\section{Um olhar para Cooperação brasileira como a África no século XXI - um olhar para cooperação técnica e econômica.}

Quando buscamos entender o lastro cooperação brasileira, em especial, de sua relação com o continente Africano não podemos ignorar o histórico que envolvem esses territórios. Uma vez que estão intimamente conectados desde o período colonial, via comércio de escravos e outras mercadorias que se desenvolvia através de conexões tendo o Oceano Atlântico como intermediário (Penha,2011).

No campo diplomático, desde meados do século XX, o Brasil busca desenvolver políticas de aproximação, seja via PEI - Politica externa independente; que buscava no governo Janio Quadros, com construção de ações diplomática alternativas, se alinhando a "países não convencionais" (países da América Latina e África) em relação a diplomacia de aproximação do países europeus e os Estados Unidos (Visentini ,2016). Todavia, embora existisse alguma aproximação com o continente africano durante o período da ditadura militar no Brasil (1964-1985), seja no reconhecimento de embaixadas de países acabaram se tornando independentes, tal como o reconhecimento de Angola em 1975, seja pela aproximação econômica e entendimento geopolítico desses países, essas aproximações não se mostraram como uma perspectiva sistemática prioritária (Cervo,2002). Dentro de uma perspectiva estratégica contemporânea, que circula nos altos escalões militares, a África seja interpretada como parte do seu "entorno estratégico". Essa é uma região onde o Brasil quer projetar sua hegemonia - diplomática, econômica e militar, o que inclui a América do Sul, a África Subsaariana, a Antártida e a Bacia do Atlântico Sul (Fiori, 2013).

Para Visentini (2016) a maior inclinação de uma política externa que sistematiza aproximações com o continente africano emerge somente nos governos democráticos, com destaque para o período de 2003-2010 [governos de Luiz Inácio Lula da Silva] quando há um redirecionamento da política externa voltada para a Cooperação Sul-Sul (Costa Lima \& Melo, 2010). A CSS, pode ser entendida como a perspectiva que busca incorporar o Brasil, como Player global e diplomático ao buscar um multilateralismo das relações, em especial diversificando regiões e buscando demandas presentes em países da periferia e semi-periferia do sistema mundial. É possível afirmar que cooperação Brasil-África se baseia na proliferação de acordos multilaterais, no aprofundamento das trocas comerciais, no aumento do intercâmbio cultural e na expansão do investimento externo brasileiro no continente no que diz respeito ao incremento tecnológico e no desenvolvimento de infraestruturas territoriais e sociais. Na qual insistimos que a cooperação técnica - como um tipo de cooperação internacional - é um elemento chave desta aproximação. 
Neste sentido, entendemos que a CSS é uma estratégia geopolitica que toma a politica externa como forma de projetar o Brasil para seu "entorno estratégico". Assim, corrobora para pensar o primeiro elemento geográfico na análise do campo da cooperação: "a projeção hegemônica e geopolítica que media novas relações de poder". Neste sentido, concorda-se com Emma Mawsdley (2015) que destaca que nesta nova conjuntura internacional emergem países que tradicionalmente não eram "doadores", a exemplo do Brasil, que aumentou sistematicamente o número de projetos e os valores empregados na cooperação técnica internacional com países do Sul Global, em especial na América Latina e na África - vide que informamos essa questão em outro texto, tendo como base os dados da Agência Brasileira de Cooperação $(A B C)$ de $2014^{2}$, que revelou o:

crescimento exponencial do número de projetos e atividades isoladas, que saiu de 17 no ano de 2003, chegando a número de 253 em 2010, que envolve 42 países no continente. Destaca-se também valor orçamentário para a África naquele ano, que ficou na ordem de $19.844,882,00$ US\$. Valor que é superior ao destinado no mesmo período para América do Sul, Central, Norte e Caribe (14.009.188,00 US\$) e para a Europa, Ásia Oceania e Oriente Médio (2.158.840,00 US\$) (Rocha, 2018, p.137)

A construção da cooperação técnica brasileira no contexto da CSS passa diretamente pela ABC (Milani,2017). Esta é uma instituição ligada ao Ministério das Relações exteriores (MRE) responsável por organizar e sistematiza as ações de cooperação seja a recebida seja a demandada.

A cooperação técnica é uma modalidade no contexto da cooperação internacional para o desenvolvimento (CID). Esse tipo de cooperação consiste na construção de acordos de ajuda em determinados setores que visam a transferência de tecnologias (sociais, científicas ou operacionais), é percebido cada vez mais a utilização desta modalidade de cooperação como uma estratégia de projeção de hegemonias por parte dos países. Ela se insere no contexto das relações Norte-Sul, com o propósito de ajuda a países mais pobres (Milani,2012) mas que foi incorporado também no modelo Sul-Sul, em especial pelos países emergentes como Brasil, Índia, China e Rússia, que possuem em maior e menor grau um potencial tecnológico que pode ser "compartilhado" ou utilizado como um "Gain" estratégico em suas projeções geopolíticas. Assim, Brasil investe na cooperação técnica no contexto da CID / pelo viés da CSS para fomentar uma certa projeção diplomática.

No tocante a cooperação técnica, a ABC classifica suas ações como: [a] projetos - aqueles destinados a grandes dimensões e de longa duração; e [b] atividades isoladas, muitas vezes são ações pontuais ou de projeção de estudos para implementação de projetos. Os chamados projetos estruturantes são aqueles que possuem maior volume de investimentos e representam grandes impactos para o desenvolvimento local/regional [ver figura 1].

\footnotetext{
${ }^{2}$ Verificar gráficos correspondentes - América do Sul e Caribe < http://www.abc.gov.br/Content/ABC/imagens/americas financeiro.png > ; e Asia, Europa, Oceania e Oriente Médio < http://www.abc.gov.br/Content/ABC/imagens/asia financeiro.png > ; e da África
} 


\begin{tabular}{|c|c|c|c|c|}
\hline \multicolumn{5}{|c|}{ Projetos Estruturantes } \\
\hline Pais & Tfino & Area & Eusutores Brasileiros & Feculsos da ABC [USS) \\
\hline Guiné-Bissau & $\begin{array}{l}\text { Centro de Formação Profissional Brasit- } \\
\text { Guiné - Bissau / Fase II - Revisão B }\end{array}$ & Educação & SENAI & $2.970 .681,60$ \\
\hline Cotton-4 & $\begin{array}{l}\text { Apoio ao Desenvolvimento do Setor } \\
\text { Algodoeiro dos Países do Cotton-4 } \\
\text { (Benin, Burkina Faso, Chade e Mali) }\end{array}$ & Agricultura & EMBRAPA & $4.380 .351,00$ \\
\hline Gana & $\begin{array}{l}\text { Centro de Hemoterapia e Doença } \\
\text { Falciforme Brasil-Gana }\end{array}$ & Saúde & $\begin{array}{c}\text { Ministério da Saúde, UFMG } \\
\text { e Hemominas }\end{array}$ & $4.500 .000,00$ \\
\hline Moçambique & $\begin{array}{l}\text { Capacitação em Produção de } \\
\text { Medicamentos Anti-Retrovirais }\end{array}$ & Saúde & Ministério da Saúde & $754.530,00$ \\
\hline Moçambique & $\begin{array}{l}\text { Implantação do Centro de Formação } \\
\text { Profissional Brasil-Moçambique. }\end{array}$ & Educação & SENAI & $3.635 .092,00$ \\
\hline Moçambique & $\begin{array}{l}\text { Apoio ao Desenvolvimento Urbano de } \\
\text { Moçambique - Fase II }\end{array}$ & Desenvolvimento Urbano & Caixa Econômica Federal & $1.236 .006,00$ \\
\hline Moçambique & UAB - Moçambique & Educação & MEC/CAPES & $488.797,00$ \\
\hline Moçambique & $\begin{array}{l}\text { Modernização da Previdência Social de } \\
\text { Moçambique }\end{array}$ & Seguridade Social & MPS/DATAPREV/INSS & $615.475,00$ \\
\hline São Tomé e Príncipe & $\begin{array}{l}\text { Centro de Formaçäo Profissional Brasil } \\
\text { - Sảo Tomé e Principe }\end{array}$ & Educação & SENAI & $4.073 .428,00$ \\
\hline Sầo Tomé e Príncipe & $\begin{array}{l}\text { Apoio ao Programa de Luta contra a } \\
\text { Tuberculose em São Tomé e Principe }\end{array}$ & Saúde & Ministério da Saúde & $1.153 .698,83$ \\
\hline São Tomé e Príncipe & $\begin{array}{l}\text { Apoio ao Desenvolvimento da Produção } \\
\text { de Artesanato em São Tomé e Príncipe } \\
\text { - Fase ll e III. }\end{array}$ & Desenvolvimento Social & Instituto Mazal & $1.250 .393,83$ \\
\hline Senegal & $\begin{array}{l}\text { Apoio ao Desenvolvimento da } \\
\text { Rizicultura no Senegal }\end{array}$ & Agricultura & EMBRAPA & $1.889 .378,00$ \\
\hline & & & Total & 26.947 .831225 \\
\hline
\end{tabular}

Figura 1 - Quadro dos projetos estruturantes para África Fonte: Site da ABC, 2018.

Todos os projetos de cooperação técnica estão baseados no "Demand Driving" (Demanda Dirigida). Isso reforça a percepção que os países solicitantes possuem do Brasil quanto sua capacidade técnica e financeira brasileira para cooperar no desenvolvimento de determinada atividade. Esses projetos em execução catalisam as potencialidades técnicas e produtivas brasileiras - uma vez que as solicitações de parcerias de cooperação técnicas evidenciam o potencial e determinadas áreas na qual o Brasil possui expertise. Isso é materializado na grande demanda de cooperação na área de saúde, educação e agricultura. Vide a tabela 1, onde são os projetos estruturantes, que em sua grande parte representam essas áreas de expertise brasileira. 
A análise dos projetos estruturantes revela essa projeção hegemônica, que é medida tanto pelo espraiamento espacial para além dos PALOP's (Países Africanos falantes de língua Portuguesa) quanto pela territorialização de Instituições Brasileiras, que se reforça com a presença do total dos projetos e atividades isoladas desenvolvidos [Ver figura 2]

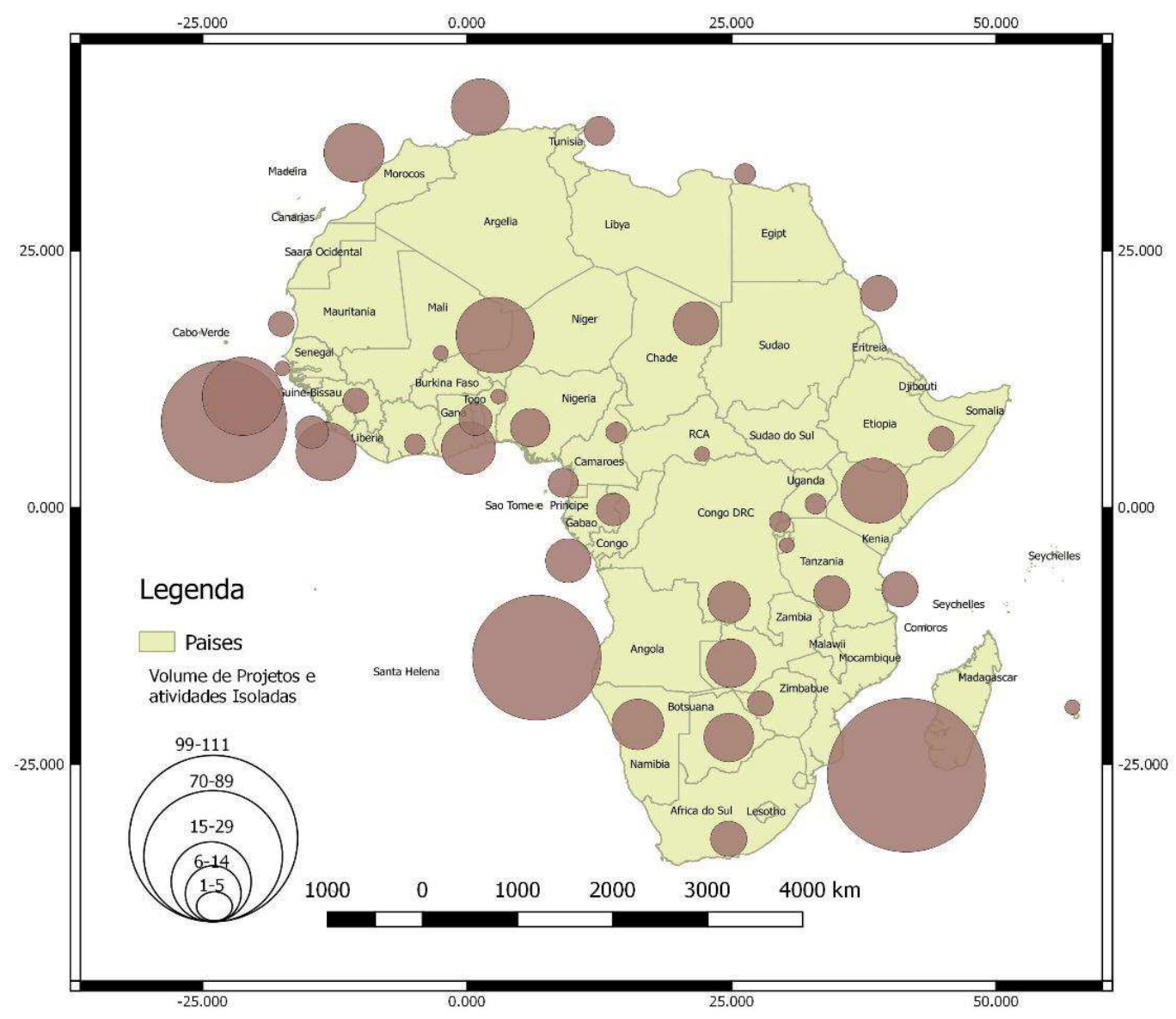

Figura 2- Mapa da Cooperação Técnica Brasileira na África com o total de Projetos e atividades isoladas Fonte: Site da ABC,2018. Org. LAGEPUFRRJ, 2018 - Fonte de financiamento: CNPq/FAPERJ

A presença dos projetos no Continente africano, revelam um espraiamento e diversificação para além dos PALOP's. Ganham destaque em volume e valores empregados na cooperação as regiões da África Ocidental e da África Meridional. A exemplo na África Ocidental, o projeto estruturante Coton4+togo, relacionado a área de agricultura, que tem como objetivo o melhoramento da produção de algodão em países como Benin, Chade, Burkina Faso, Mali e, agora incluindo o Togo, empregou a ordem de 4.380.351,00 US\$. Na área de agricultura, destaca-se também o projeto para desenvolvimento da Rizicultura no Senegal que empregou uma ordem de 1.889.378,00 US\$. Nesta mesma região, podemos mencionar o projeto estruturante de maior valor empregado que foi aplicado em Gana. O Centro de Hemoterapia e doenças falciforme Brasil-Gana contou com o apoio do Ministério da Saúde, da UFGM e do Hemominas e teve o valor empregado de 4.500.000,00 US\$. Para a África Meridional, destaca-se a importância tanto de Moçambique quanto de Angola que 
possuem um número considerável de projetos e valores empregados, na qual destaca-se o primeiro por concentrar 5 projetos estruturantes. Mas ganha destaque também países como Namíbia, Botsuana e Zâmbia, que apresentaram quantidades significativas de projetos em desenvolvimento e ações isoladas. A cooperação Técnica Brasileira na África é marcada pela transformação material no território, que compreende tanto a territorialização de empresas e instituições Brasileiras, com maior destaque para Embrapa e a Fiocruz - que representam notoriamente o know-how brasileiro nestes setores de agricultura e saúde; e a transformação de bases e dinâmicas econômicas em muitas locais onde esses projetos se desenvolvem - vide o papel dos projetos na área de agricultura que dinamizam setores da agricultura familiar e melhoramento da produção de produtos de exportação.

Outrossim, não se pode ignorar a porção setentrional do continente africano, que vem marcando alternativas para o avanço de capitais brasileiros, em especial pelo volume que representam em negócios com o Brasil (ver figura 3).

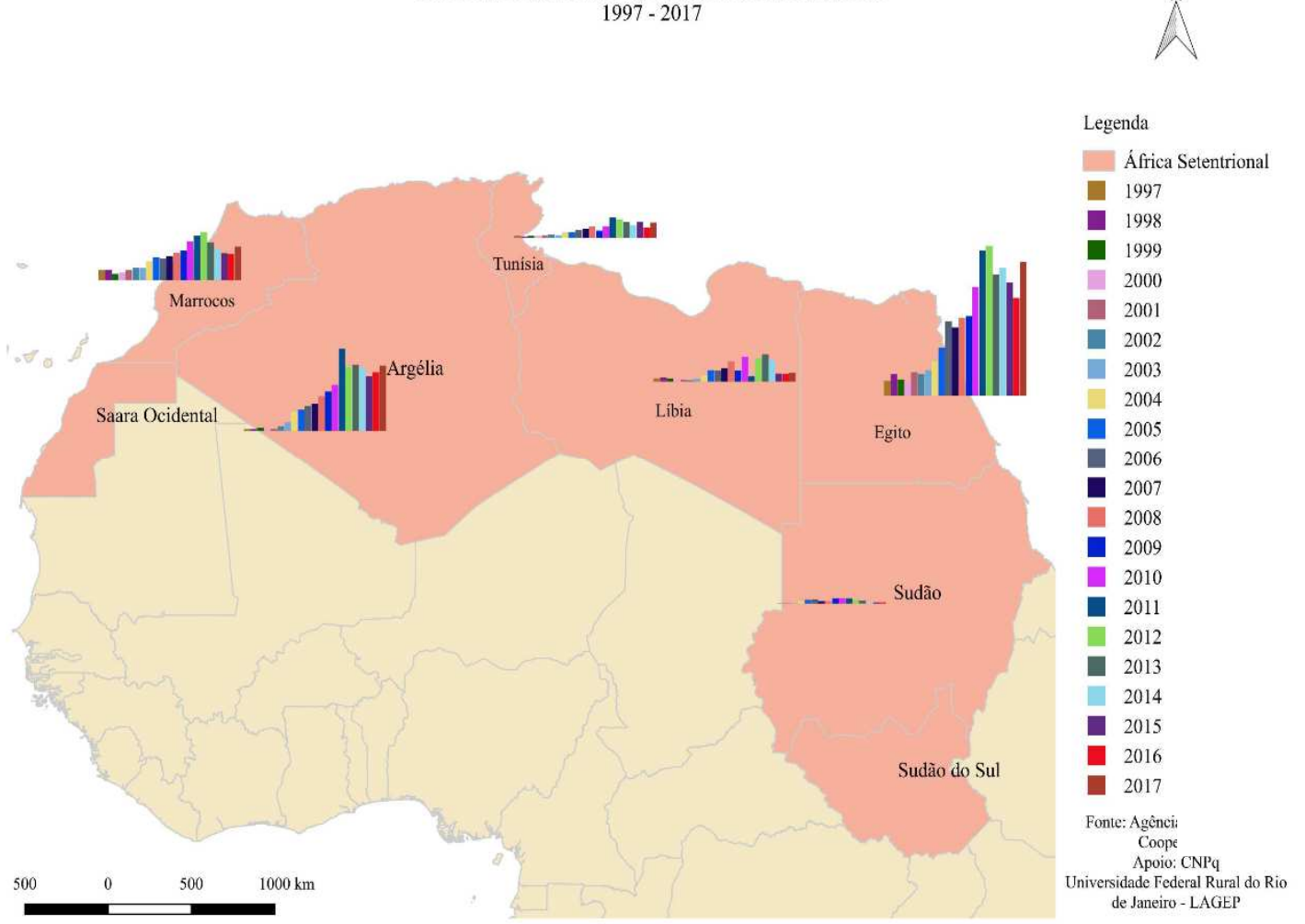

Figura 3 - Mapa da série histórica das exportações Brasileiras para África 1997-2017. Fonte: MIDC, 2018.

O mapa anterior (figura 3) permite visualizar o resultado da aproximação brasileira com a África Setentrional por destacar que após 2003 há um crescimento sensível do volume de exportações para essa região do continente. Ganham destaque os seguintes países: Egito, Argélia, Marrocos e Tunísia. Segundo dados do Ministério da Indústria, Comercio Exterior e Serviços (MDIC 2018), esses representaram juntos no ano de 2010 o somatório de 2.959.257.787 FOB(US\$) enquanto em 2003 
representavam apenas $740.415 .434 \mathrm{FOB}(\mathrm{US} \$)$, consolidando no período informado um crescimento superior a 390\% nas exportações. Esses países além de serem importante produtores de petróleo, são aqueles que adquiriram produtos brasileiros do reino animal (carnes) e produtos de indústrias alimentares (café, cereais, sementes e frutos oleaginosos), se tornando os principais produtos exportados para essa região da África.

\section{Alguns apontamentos finais - uma síntese e o que esperar da política externa brasileira.}

A busca por consolidar ações de cooperação técnica econômica com países menos capacitados baseado no que ABC, chamada de "Demand Driving", reforçou a tentativa brasileira de construir um novo marco estratégico numa geografia global em mudança. Ganharam destaque os grandes investimentos nos setores de cooperação técnica na área de educação, saúde e agricultura feitos no continente africano, que superaram os valores para as demais regiões do mundo, materializando influências e expressivos retornos econômicos e diplomáticos em regiões da África Meridional, Ocidental e Setentrional e que revela profundas contradições internas (com esgarçamento do orçamento governamental interno do MRE e lastros indicativos de corrupção) e externas (com atividades sistêmicas de exploração e espoliação no continente africano).

Isto tem revelado ao mesmo tempo: [a] a expansão econômica e produtiva brasileira na escala mundo - retomando uma dimensão hegemônica de sua condição que almeja, entre outras coisas, a vaga como membro permanente do conselho de segurança da $\mathrm{ONU}$; e [b] territorialização de suas empresas privadas e estatais que ganham com a manutenção de novos acordos técnicos e econômicos - revelando uma capacidade de operacionalização e de dimensionamento das demandas de expansão econômico-técnico-produtiva territorializada em outras escalas.

Reforçamos aqui que a ênfase na cooperação Sul-Sul, tomada no período de 2003-2010 revelou-se como um pilar importante na consolidação das estratégias brasileiras na sua afirmação no sistema econômico mundial. Isso demonstra um retorno relevante da projeção Geopolítica Brasileira que pode conferir um up grade em sua posição econômico produtiva, uma vez que a cooperação técnica revela seu Know-How tecnológico e a cooperação econômica permite o espraiamento de capitais Brasileiros e possibilidades de novos negócios que são rentáveis. Do outro lado, não se pode ignorar as demandas locais e os inúmeros questionamento das ações territorializadas por parte de comunidades locais em diferentes pontos na África que denunciam atitudes brutais de empresas e instituições brasileiras, seja pela intensificação da exploração e poluição ambiental, seja pela expropriação de terras, ao modelo "acumulação via espoliação" mencionado por David Harvey.

Segundo inúmeros autores (Leite,2011, Cervo, 2003, Visentini, 2013 e 2010) a política externa brasileira acaba repercutindo os reflexos do posicionamento da política interna. Desde agosto de 2016, tem se percebido mudanças nas orientações da política externa uma vez que ocorreu uma mudança no executivo brasileiro via Impeachment da presidente Dilma Rousseff, reverberando na política externa com valorização de tendências de aproximação com os Estados Unidos, vide os pronunciamentos do então chanceler Brasileiro José Serra em 2016. De fato, entendemos que a 
construção de uma agenda de política externa deve preconizar os interesses de cunho geopolítico e geoeconômicos bem como pensar em matrizes solidárias que permitam o desenvolvimento dos povos.

Em suma, por todos os pontos apresentados, se torna relevante uma análise geográfica destas relações sobre a cooperação técnica e econômica Brasileira com os países Africanos, uma vez que permitem analisar estratégias de consolidação numa ordem global em mudança além de reafirmar a importância da análise geográfica no contexto de globalização.

\section{Bibliografia.}

Arendt, Hannah. (2009). O que é política? Rio de Janeiro: Bertrand Brasil.

Allen, Jonh. (2003). Power. in: Agnew, J. et all. A Companion to political Geography. Oxford: Blackwell. pp.95-108.

AGÊNCIA BRASILEIRA DE COOPERAÇÃO. (2013). Manual da gestão da Cooperação técnica SulSul. Brasília: ABC.

Bini, Valério.(2016). Coperazione allo sviloppo in Africa. Teorie, politiche, pratiche.Mlmezis edizione, Milão.

Cervo, Amado Luiz. (2003) Política exterior e relações internacionais do Brasil: enfoque paradigmático. Revista Brasileira de Política Internacional. Vol. 46, n. 2, 5-25.

Cervo, Amado Luiz. (2002) Relações internacionais do Brasil: um balanço da era Cardoso. Revista Brasileira de Política Internacional, ano 45, n. 2, 5-35.

Costa Lima; M. F.; Nelo, V. D. S. (2010) Revalorização do lugar da África: Política de desenvolvimento e as relações Sul-Sul no Governo Lula da Silva. SÉCULO XXI, Porto Alegre, v. 1, n.1, jan-dez, 127-155.

Dansero, E. et all. (2008). Geografia e cooperazione allo sviluppo. Temi e prospettive per un approccio territoriale. FrancoAngeli: Milão, 2008.

Fiori, José Luis da Costa. (2013) O Brasil e seu "entorno esatratégico" na primeira década do século XXI. IN: Lula e Dilma; 10 anos de governos pós-neoliberais. (pp. 31-53.) Rio de Janeiro: Boitempo.

GECO. (2016). Lasciarsi provocare dal mondo.geografia e Cooperazione allo sviluppo: una relazione Antica, un dibattito attuale. Rivesta. Geografia. Italiana. 124, 347-358.

Hurrel, Andrew. (2008). Hegemonia, Liberalimo e ordem global: Qual é o espaço para as potências Emergentes?. In Lima, et all. Os Brics e a ordem Global.(pp.9-42) Rio de Janeiro: FGV editora,

Leite, P. S. (2011) O Brasil e a cooperação sul-Sul em três momentos de política externa: os governos Jânio Quadros/João Goulart, Ernesto Geisel e Luiz Inácio Lula da Silva. Brasília: Fundação Alexandre de Gusmão.

Lima, M.RS; Milani, C. (2016). Política Externa, Geopolítica e Modelos de Desenvolvimento. In: LIMA, Maria Regina Soares et all (org's). Cooperacíon Sur-Sur, política exterior y modelos de desarrollo en América Latina. (pp. pp.21-39). Buenos Aires: CLASCSO.

Milani, Carlos. (2017). ABC 30 anos. História e desafios. Brasília: Agência Brasileira de Cooperação.

Milani, Carlos. (2012). Aprendendo com a história: críticas àexperiência da Cooperação Norte-Sul e atuais desafios à Cooperação Sul-Sul. Card.CRH, Salvador, v. 25, n. 65, Maio/Ago, 211-231.

Mawdsley, Emma; Kim, Sung-Mi; Marcondes, Danilo (2017): Political leadership and 'non-traditional' development cooperation, Third World Quarterly, 1-17. Disponível em < http://dx.doi.org/10.1080/01436597.2017.1333416 > [ Acedido em 15 de junho de 2017] 
Mawdsley, Emma. (2015) Development geography 1: Cooperation, competition and convergence between 'North' and 'South'. Progress in Human Geography,1-10.

Mawdsley, Emma. (2012.). From Recipients to Donors: Emerging Powers and the Changing Development Landscape. London: Zed Books

Marcondes, Danilo; Mawdsley, Emma. (2017) "South-South in Retreat? The Transitions from Lula to Rousseff to Temer and Brazilian Development Cooperation." International Affairs 93, no. 3, 681-699.

Pautasso, Diego. (2010). O fortalecimento das relações sul-sul: estratégia e realidade para os países emergentes. Revista Conjuntural Austral, vol.2, no8 out-nov, 48-62

Penha, Eli Alves.(2011). Relações Brasil-África e Geopolítica do Atlântico Sul. 1. ed. Salvador: EDUFBa.

Rocha, André Santos. (2018). "A política externa e geopolítica brasileira na era Lula: uma análise dos acordos de cooperação técnica para a África". In: RÜCKERT, A. A.; SILVA, A. C. P. da; SILVA, G. de V. (Orgs.). Geografia Política, Geopolítica e Gestão do Território: integração sulamericana e regiões periféricas. (pp. 123-136) PortoAlegre: Editora Letra1.

Rocha, André Santos. (2014). Território e Hegemonia no tear das Relações Internacionais na cooperação Sul-Sul: Apontamentos sobre a aproximação Brasil-África. In: Anais do I Congeo. Porto Alegre / Rio de Janeiro: Editora Letra 1/ REBRAGEO, v. 1. p. 39-48.

Sanguin. André-Louis. (2016) A evolução d Geografia Política desde os anos de 1990: uma perspectiva internacional. In: SILVA, A.C.P. Geografia Política, Geopolítica e Território: racionalidades e práticas em múltiplas escalas. (pp.13-64.) Rio de Janeiro, Gramma.

Stuenkel, Oliver. (2017) BRICS e o futuro da ordem mundial. Rio de Janeiro/São Paulo; Paz e Terra.

Visentini, Paulo Fagundes. (2016). A relação Brasil-África. Prétigio, cooperação ou negócios? Rio de Janeiro: Ed. Altabooks.

Visentini, Paulo Fagundes. (2013). A projeção Internacional do Brasil 1930-2012. São Paulo: Elseuvier.

Visentini, Paulo Fagundes. (2010). Cooperação Sul-Sul, diplomacia de prestígio ou imperialismo "soft"? as relações Brasil-África no governo Lula. Século XXI, Porto Alegre, V. 1, №1, jan-dez, 65-84.

Valcarcel, José Ortega. (2000). Los horizontes de la geografia, teoria da La geografia. Barcelona: Ariel, 2000.

\section{Agradecimentos.}

Agradeço ao Conselho o Nacional de Pesquisa (CNPq) que apoio no desenvolvimento da pesquisa - protocolo: 470176/2014-8, por intermédio da chamada MCTI/CNPQ/MEC/CAPES № 22/2014 - CIÊNCIAS HUMANAS. Também agradecemos o apoio da Pró-Reitoria de Pós-Graduação da UFRRJ, com apoio para participação e apresentação deste trabalho através do edital de Internacionalização 2018, no referido evento que dá origem a este e-book realizado na FLUP Uporto no mesmo ano. Também agradecemos ao CNPq por conceder bolsa PIBIC para discente Mariana Herreira Pértile, que contribuiu na elaboração do Mapa de exportação brasileira para África Setentrional (figura 3). Bem como agradecemos a comissão organizadora do evento, pelo apoio logístico e científico e das discussões que foram propostas. 